\title{
Human Resources Management Research of Enterprise Strategy under the Perspective of Life Cycle
}

\author{
ZHOU Fang \\ School of electronic commerce, Nanyang Institute of Technology,Nanyang 473004,China \\ zhoufang@126.com
}

\begin{abstract}
Keywords: Life cycle, enterprise strategy, human resource management
Abstract. Social economy enters into a rapid development stage; the knowledge economy age has come. How to establish scientific development strategy for enterprises in the development process is to ensure that the enterprises play an important role in improving competitiveness in the process of development. Under the perspective of life cycle to study enterprise's trajectory is necessary for the study of enterprise human resource management. This paper based on the perspective of life cycle theory studies enterprise strategic human resources management in order to improve the core competitiveness of enterprise and to seek the better development, for the enterprise.
\end{abstract}

\section{Introduction}

Everything in the world has a certain growth trajectory, the development of the enterprise is not exceptional. Enterprise life cycle is just like a pair of hands to control the enterprise's development trajectory. Enterprise life cycle can be divided into natural life cycle and legal life cycle. Different life cycle stages, the enterprise competition strategy and characteristics are also show the different characteristics, therefore in the life cycle perspective study of strategic human resources management of enterprises has important strategic significance.

The concept of enterprise life cycle.The development of enterprise life cycle is the enterprise growth trajectory, dynamically reflects the enterprise's development, growth, maturity and decline and etc. Main purpose of enterprise life cycle theory is to find a particular organization structure form be able to adapt to and its characteristics, and constantly promote the development of continuation in the different stages of enterprise life cycle, so as to make the enterprise find a relatively optimal mode to keep the enterprise development ability from the aspects of the internal management, and ensure enterprise be able to exert advantage at different stages of life cycle, as far as possible the extension of life cycle, to realize the sustainable development of enterprises. At present there are two main types of lifecycle methods, one is the industry life cycle/product life cycle point of view, this view relatively traditional; the other is a demand for life cycle, this view is more challenging. Enterprise life cycle has certain regularity; in general, the enterprise will be fixed through common phase and phase fluctuations and dull.

The source and development rule of enterprise life cycle. Enterprise life cycle, this concept was first put forward in 1972 by Jason grimier taught at Harvard University in the United States, the in the Evolution of the Organization to Grow and Change, later Iraqi love Dean draw the enterprise life cycle diagram, the American scholar in 1989, he thinks enterprise life cycle and the life cycle of basically the same (in the order: incubation period, infancy and toddler period, puberty, mature period, stable period, noble, bureaucratic, bureaucratic period, early death). He shows for different life cycle stage characteristics, and put forward corresponding countermeasures, reveals the law of development of enterprise life cycle, survival in the process of the basic development and the relationship between constraints and revealed. Later, more and more scholars continuously research and perfect the enterprise life cycle theory. There are more than 20 kinds of model of life cycle phase. The early stages of the enterprise survival ability is weak, once the development of enterprises to survive, enterprises will enter a rapid growth, the company a significant increase in the scale of the enterprise's remarkable increase of economic strength and the enterprise's market share increase, the enterprise after entering mature period, capital, talent, become the leader of the industry, however, 
companies in the late mature problem such as higher costs and benefits of decline, if the enterprise can't change the status quo, well will toward recession.

\section{Human resource management and enterprise development strategy}

Human resource management strategy. Strategic human resource management refers to the organization in order to achieve the goal, and take the strategic significance, planning a series of management behavior and human resources deployment. This concept was first put forward by the American, however, Japanese companies was one of the earliest practitioners of strategic management. Japanese enterprise human resources management focuses on the manager, and in this theory under the guidance of the implementation of the series has the management system of humanistic thought, implemented by capacity, quality, skills, education degree, adaptability to complete the task and working performance on the basis of strategic management. After the 1980s, the discussion of this idea and research gradually get thorough, the United States, Europe and Japan enterprise management practice demonstrated that with the continuous development of economic society, more and more enterprises in our country began to realize the advantages of human resources in the enterprise development, and began to rely on human resource advantage to improve competitiveness.

The function of human resource management in the development strategy of enterprise. Enterprise development strategy is based on the actual development of the enterprise condition as the foundation, and the development of the vision of the enterprise as the goal, and with time as the connection, and according to the different developmental stages of the enterprise to complete the task of effective resource configuration. Enterprise strategy can achieve successes mainly depends on different stages and the improvement of enterprise competence, human resources as an important carrier in the enterprise management ability plays an important role in the development strategy of the enterprise. Market competition is fierce in modern society, science and technology changes everyday, the importance of talent in enterprise development gradually appears, so more and more enterprises attach importance to the role of human resource management to strategic, at the same time in the fight for market share began to take measures to introduce talents, retain talents.

The development of human resource management is not a fixed pattern, different age, different enterprise nature, then the human resources management way also changes following, human resource managers in management must therefore can play full the subjective initiative, so as to make the talents play a full role in the development of enterprise, promote enterprise stable, high-speed development. In the era of knowledge explosion, talent has become a core to the enterprise and social development, the enterprise of different life cycle stage, the role of human resource management is different. In the initial stage, human resources mainly introduce talents for the enterprise for reserves; in mature stage, human resources management is focused on the control of personnel growth working with elite talent and reducing the cost; going into recession, the enterprise's human resources management should start to optimize the structure of compact, so human resource managers must accurately grasp the pulse of the development of the enterprise and the trajectory, step at the height of the overall management so as to do a good job in human resources management.

\section{Enterprise strategy human resource management under the perspective of life cycle}

Characteristics and countermeasure of human resource management in the entrepreneurship stage. At the startup phase of the enterprise, all aspects are not mature, and enterprise funds available is less, the enterprise should put the priority on the survival and development, from start-up period into development as soon as possible. At this stage, the enterprise well-knowingness, the social recognition is not high, the weaker, enterprise management and the rules and regulations are not perfect, so in the human resources management has more strong man color, the backbone of the enterprise is mainly entrepreneurs, entrepreneurs as the main members of the enterprise, the role of the individual is very outstanding, enterprises show the growth and flexibility characteristics. In this 
stage, the enterprise in the initial stage, the work is difficult, to be able to select excellent talents for the enterprise success or failure of a key role.

In the entrepreneurial stage, the core of enterprise human resources is the key to obtain and absorb talents for the enterprise development needs, so as to satisfy the business enterprise development. In order to ensure the rapid development of the enterprise, human resource management can absorb and cultivate talents through the following measures to: (1) absorb the talent mainly through external obtain and internal mining two ways due to less talent cultivation at startup enterprise, therefore to realize the internal mining basic is impossible, can only through external access this channel to obtain talents. First of all, enterprises should strengthen the contact with professional personnel structure, real time control the supply of talent information. There are many domestic recruitment agencies currently, such as Alliance, 58, space-based talent net, and etc. Secondly, in the selection of key talents, besides the professional quality of talents, enterprise should also pay attention to talents work experience, outstanding performance as the basic indicators. Due to early talent demand is relatively small size, so companies can work the application of high positioning, thus reduce the enterprise cost of capital when screening and the practice. Startup enterprise economic foundation is weak, this time by high basic impossible to attract talent, so when enterprise in the recruitment will work challenging and good prospects for development as the main point of interest, so as to attract more talents, of course, pay also need to market basic same. Enterprise can also through the transfer of stock options and other methods to the interests of employees and enterprise long-term interests, achieve the long-term stable development of the enterprise. (2) Cultivate talents, after recruiting talents, how to cultivate talents for the long-term development of the enterprise has become the extremely important strategic significance. So the enterprise managers must attach great importance to the cultivation of the talent, and specify the core talent training plan, make the career planning and development of enterprise corresponding; companies must foster a sound environment for talents, make it to participate in the enterprise management practice, providing talent show platform.

Characteristics and countermeasure of human resource management in the growth stage. After the development of the early running, the competition enhances obviously. And with the expansion of business, enterprise's main business is bound to the fast growth, all kinds of resources demand increase in the process of enterprise development. Enterprise gradually become regularized, continuously improves various rules and regulations, at this point, the entrepreneurs play the role of managers and leaders more, have more requirements on the human resources, so the countermeasures of human resources management strategy also change accordingly. First, enterprise human resources management departments should forecast and plan the number of people and the direction to formulate the corresponding human resource planning. In general, the enterprise needs large numbers of talents at the growth stage, requests talented person immediately get started at the same time, so the human resource management in the recruitment needs to choose people having working experience also having good talent. Second, human resource management group works on full analysis of established standards so as to realize the standardized management of talent; also, the human resource management department can establish good contact with the human resources market, through multiple channels to grasp talent, and can achieve the enterprise needs to human resources. Finally, enterprises need to improve the system of talent management, training, reward and promotion, and improve the business level and work enthusiasm, promote the rapid development of the enterprise. At this stage, the enterprise human resources management is hard to work and strength, it is for human resources management personnel's quality put forward higher requirements, so the need for a human resources construction in the same period.

Characteristics and countermeasure of human resource management in the mature stage. This stage is the ideal stage, the whole life cycle of enterprise after a certain time of development, growth, flexibility and competitive achieves the ideal state, enterprise can gain maximum profits, financial position was changed a lot, cash flow is relatively ample, at the same time, improve the structure and system of enterprise area. At the start of the enterprises pay attention to the image of the enterprise, pay attention to the needs of customers, adhere to the principle of customer needs first, in this peak period, the choice of enterprises directly determines its development direction, in particular 
there are three main types: (1) after the recession;(2) business leaders sober, fine-tuning the enterprise structure, mechanism, etc., as the extension of enterprise maturity;(3) enterprise management and workers all keep a clear mind, adhere to the development and innovation, steady drive enterprises to enter new growth.

In order to improve the situation, the enterprise human resources management can adopt the following countermeasures: (1) perfect the staff performance appraisal system, in the index increased evaluation index system of innovation, enhance innovation index weight;(2) the management of human resources policy adjustment, the promotion, distribution, and reward priority innovation department, contribution and attitude of the staff.(3) the employees training, improve the staff's innovation ability and skills, promote crisis education, so as to enhance the power of talent;(4) to strictly control the external personnel to enter, refused to mediocrity, when talent into the comprehensive ability evaluation, pay attention to talents' innovative ability, positive innovation ability of talents.

Characteristics and countermeasure of human resource management in the decline stage. At this stage, enterprise's vitality and power are almost lost, lost the ability to innovate, facing the crisis of bankruptcy, which mainly shows in the following characteristics: loss of profits, internal bureaucracy in the enterprise, useless system, ineffective execution, lack of growth and flexibility, drop of the market share. Human resource management shows the following characteristics: the heart instability, core brain drain, increasing of the labor costs, abates of the enterprise centripetal force. In order to change the status, enterprise human resources management should promote the development of enterprise through the following countermeasures: (1) science layoffs; when enterprise develop to this stage, profit decreases apparently, some companies even have difficulty in capital turnover, which can reduce the enterprise cost by reducing the useless. When layoffs, adhere to the principle of fair, open, fair, on the basis of perfect assessment system and comprehensive performance to layoffs, realize the competition. (2) to strengthen the human resources cost control; the enterprise should adjust compensation policies, using high elastic compensation mode, which will be combined closely with the employees' income and personal contribution, work more, paid more.(3) to adjust the personnel policy; talents get promoted and inability people layoff to retain talent.

\section{Summary}

Enterprise's life cycle is the route for enterprise's development, and the introduction of talents and training have a vital significance for enterprise's survival and vitality. In order to achieve long-term development, enterprise needs to adopt flexible employment system combined with different stages to ensure that enterprises can be in an impregnable position in the strategic turning point.

\section{References}

[1] Izac Eddie. The pursuit of its great prosperity [M]. Beijing: huaxia publishing house, 2004.

[2] Pan Yongming, Mi Guangxu. Strategic human resource management: to win competitive advantage for organization [J]. Journal of jiangxi social science, 2009 (5).

[3] Zhao Lijuan. The inner mechanism of continuous growth of the enterprise - based on the theory of the growth dynamics research [J]. Science and technology management research, 2011, (16).

[4] Pi Guimei. Development strategy research of small and medium-sized enterprise in Jiangxi province based on the theory of the life cycle[J]. Journal of social science in Jiangxi province, 2011, (10). 